\title{
PATTERN OF PSYCHIATRIC REFERRAL FROM EMERGENCY DEPARTMENT OF A TERTIARY LEVEL HOSPITAL IN NEPAL
}

\author{
Sanjeev Ranjan ${ }^{1}$, Reet Poudel $^{2}$, Pradeep Pandey ${ }^{3}$
}

\section{ABSTRACT}

INTRODUCTION: Emergency department serves as one of the gateway through which patients with psychiatric disorders come for treatment. The referral to the psychiatry department enables a psychiatrist to provide services to these patients in need. So, the study of this pathway of care becomes important.

MATERIAL AND METHODS: A total of 100 consecutive patients referred from emergency to the department of psychiatry were enrolled in this study. Their socio-demographic variables, reason and purpose for referral was assessed. The psychiatric diagnosis was made according to the International Classification of Diseases -10 (ICD-10) system.

RESULTS: The psychiatric referral rate from the emergency was found to be $8.46 \%$. Out of one hundred patients more referred patients were female (64\%), from rural background (90\%). Family members were the source of referral for emergency visit in most of the patients (74\%). Dissociative disorder was the most common diagnosis (26\%) followed by acute $\&$ transient psychotic disorders at $12 \%$.

CONCLUSIONS: Fewer patients are referred to psychiatry department even in a tertiary level hospital of Nepal.

KEYWORDS: Emergency Department; Psychiatric referral

1. Associate Professor, Department of Psychiatry, Universal College of Medical Sciences \& Teaching Hospital, Bhairahawa, Nepal

2. Postgraduate Resident, Department of Psychiatry, Universal College of Medical Sciences \& Teaching Hospital, Bhairahawa, Nepal

3. Consultant Psychiatrist, Department of Psychiatry, Alka Hospital, Kathmandu, Nepal

\author{
For Correspondence \\ Dr. Sanjeev Ranjan \\ Associate Professor, \\ Department of Psychiatry, \\ Universal College of Medical Sciences \& Teaching \\ Hospital, Bhairahawa, Nepal \\ E-mail: drsanjeevranjan@yahoo.com
}




\section{INTRODUCTION}

In today's era, patients with psychiatric disorders seek treatment either through the emergency department or the outpatient psychiatric departments run by different multidisciplinary hospitals. Many patients admitted in psychiatric wards come from the emergency department. The emergency department of general hospitals encounters patients with wide variety of presenting complaints including those related to the psychiatric discipline. As this department is an important component in the psychiatry services, world health organization had stressed the need for evaluation of the emergency services. They concluded that the proper creative handling of the first contact is vital to the quality of the subsequent care of the patient and his/her family. ${ }^{1}$ A psychiatric emergency is defined as "any disorder of mood, thought and/or behaviour which arises suddenly and requires prompt action and for which a patient presents to a health care facility".

J. Brothwood pointed out three distinct functions for the psychiatric emergency clinic: a rapid psychiatric evaluation for patients referred by family doctors, responsibility for the correct allocation of patients to the available services and an advisory service for old and current patients of the hospital. ${ }^{2}$ Studies of psychiatric referrals from emergency department have always raised interest among researchers. Such studies provide us data about the prevalence of the psychiatric illnesses and also the attitude and awareness of the medical profession to the discipline of psychiatry.

Though psychiatric services are available in almost all teaching hospitals in Nepal, little is known as to why and how frequently the psychiatrist is called in emergency department and what the magnitude of the problem is. The present study aims to assess the referral pattern, socio-demographic variable of the referred patients, source of emergency referral, mode of referral, reason and purpose of referral, presenting complaints and their psychiatric diagnosis.

\section{MATERIALAND METHODS}

This study was conducted in the emergency department of the Universal College of Medical Sciences, Bhairahawa, Nepal, from $12^{\text {th }}$ December 2012 till $15^{\text {th }}$ February 2013.Universal College of Medical Sciences is a 750 bedded teaching hospital located in south-western part of Nepal.

Department of psychiatry here provides OPD service and inpatient care through its 70 bedded ward; the largest of its kind in Nepal. Patients with psychiatric emergency and nonemergency complaints after the OPD hours attend the emergency department of this college which runs 24 hour services. The patient is first evaluated by an emergency doctor on duty and if in his assessment it is an emergency, the patient is registered and given a registration number. Consultation with a specialist is sought if the resident doctor feels that the services of the specialist are needed in the evaluation and management of the patient.

During the study period the authors attended the emergency referrals round the clock and provided the necessary consultation and management. One hundred consecutive emergency referrals were taken for the study. Only those patients who consented to participate in the study were enrolled. The socio-demographic and various clinical variables were noted in the semistructured self-designed proforma. Psychiatric diagnosis was made according to the International Classification of Diseases, $10^{\text {th }}$ edition (ICD 10) developed by the world health organization in 1992. Ethical clearance was obtained from the ethical review board of the institute before conducting the study. Descriptive statistics was used to analyze the data.

\section{RESULTS}

During our study period of 66 days, total one thousand six hundred and forty three patients attended the emergency service. Out of them psychiatric referral was made in one hundred and thirty nine patients. One hundred consecutive patients were selected for the study.

We found the psychiatric referral rate from the emergency to be $8.46 \%$. More patients fell in the age group of 20- 24 years $(19 \%)$ and $25-29 y r s ~(19 \%)$ followed by $15-19 y r s ~(13 \%) ., 30-$ $34 \mathrm{yrs}(11 \%) 35-39 \mathrm{yrs}(11 \%), 40-44 \mathrm{yrs}(7 \%), 45-49 \mathrm{yrs}(5 \%)$, $50-54 \mathrm{yrs}(4 \%), 55-59$ yrs $(5 \%), 60-64 \mathrm{yrs}(2 \%), 10-14 \mathrm{yrs}$ $(2 \%), 65-69$ yrs (1\%) and above 70 years $(1 \%)$.

In our study more referred patients were female with male to female ratio of 1:1.78. Most of our referral patients were from rural area (90\%) and Hindu by religion (92\%). Regarding marital status $74 \%$ of our patients were married while $20 \%$ were unmarried, $4 \%$ were divorced and remaining $2 \%$ were widowed.

More patients belonged to Brahmin caste (25\%) followed by 
tharu (15\%), chhetri (14\%) magar (11\%) and others. Twenty six percent of the patients referred were illiterate, $20 \%$ had studied up to primary class, $15 \%$ lower secondary, $14 \%$ were literate only, $14 \%$ had education up to secondary level, $7 \%$ had higher secondary level education. Only 4\% were graduate. $25 \%$ of the patients were housewife, followed by farmer $(19 \%)$, students (14\%) and others. Ten percent of the patients were unemployed.

Family members were the source of referral for emergency visit in majority of the patients (74\%). Private practitioners were the source of referral for emergency visit in only 9 percent of the patients. Majority of the psychiatric referral in the emergency was made by the emergency doctors or medical officers on duty (88\%). Nine percent of the psychiatric referral was made by the department of medicine, $2 \%$ by department of orthopedics and $1 \%$ by department of obstetrics and gynecology.

As shown in the figure. 1 below, the reason for referral was predominant psychiatric symptoms in $40 \%$ of the cases followed by mental illness co-existing with physical illness in $24 \%$. Psychiatric referral was made in $19 \%$ of the cases as no physical illness was found in them.

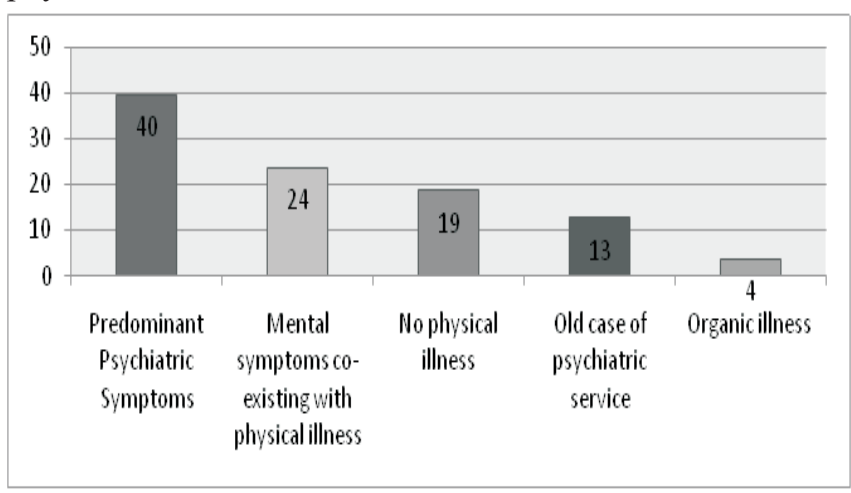

\section{Figure 1: Reason of psychiatric referral}

The most common purpose behind psychiatric referral in the emergency department was for the psychiatric management itself. In next $30 \%$ of the cases the purpose for referral was to rule out psychiatric illness. In $15 \%$ of the cases it was for management of associated psychiatric symptoms. Evaluation of psychiatric medication of the patients who present with symptoms of other specialties but were on psychiatric medications, counselling and suicide prevention were the other purposes for psychiatric referral.
Table 1: Purpose of referral

\begin{tabular}{|l|l|}
\hline Purpose & Total Patients/\% \\
\hline For Psychiatric management & 46 \\
\hline To rule out psychiatric illness & 30 \\
\hline Associated Psychiatric Management & 15 \\
\hline Counseling & 3 \\
\hline For evaluation of Psychiatric medications & 3 \\
\hline Sucide prevention & 3 \\
\hline
\end{tabular}

Irrelevant talks was the most common presenting complaints (29\%) followed by fainting spells $(13.67 \%)$, excitement and violence $(11.33 \%)$ and others as shown in table 2 .

\section{Table 2: Symptoms}

\begin{tabular}{|l|l|l|}
\hline Complains & Total responses & Total \% of symptoms \\
\hline Irrelevant talks & 60 & 20 \\
\hline Fainting spells & 41 & 13.67 \\
\hline Excitement and violence & 34 & 11.33 \\
\hline Somatic symptoms & 31 & 10.33 \\
\hline Disturbed sleep & 27 & 9 \\
\hline Headache & 21 & 7 \\
\hline Altered mood & 17 & 5.67 \\
\hline Altered sensorium & 12 & 4 \\
\hline Anxiety symptoms & 10 & 3.33 \\
\hline Decreased appetite & 10 & 3.33 \\
\hline Diziness & 7 & 2.33 \\
\hline Seizure & 5 & 1.67 \\
\hline Sucidal ideas/acts & 3 & 100 \\
\hline Others & 22 & \\
\hline Total & 300 & \\
\hline
\end{tabular}

Regarding the psychiatric diagnosis, mostly patients with dissociative motor disorders (25\%) presenting to emergency were referred to psychiatrists followed by alcohol related disorders (13\%), acute and transient psychotic disorders $(12 \%)$, depressive disorders $(9 \%)$, schizophrenia $(8 \%)$, bipolar affective disorders $(8 \%)$ and others, as shown in table 3 below. 
Table 3: Diagnosis

\begin{tabular}{|c|c|c|c|c|}
\hline ICD code & Psychiatry Diagnosis & Male/ \% & Female/ \% & Total/ \% \\
\hline F00-09 & Organic Disorders & 1 & 1 & 2 \\
\hline F10-F19 & Psychoactive substance use & & & \\
\hline F10 & Alcohol & 12 & 1 & 13 \\
\hline F12 & Cannabinoids & 1 & 0 & 1 \\
\hline F20-F29 & Sizophrenia, schizotypal & & & \\
\hline $\mathrm{F} 20$ & Schizophrenia & 6 & 2 & 8 \\
\hline $\mathrm{F} 23$ & Acute \& transient psychotic disorders & 2 & 10 & 12 \\
\hline F30-F39 & Mood [affective] disorders & & & \\
\hline F30 & Maniac episode & 1 & 2 & 3 \\
\hline F31 & Bipolar affective episode & 5 & 3 & 8 \\
\hline F32 & Depressive episode & 4 & 5 & 9 \\
\hline F33 & Recurrent depressive disorder & 1 & 2 & 3 \\
\hline F40-F48 & Neurotic, stress related, somatoform & & & \\
\hline F41.1 & Generalised anxiety disorder & 1 & 1 & 2 \\
\hline F43.1 & Posttraumatic stress disorder & 1 & 0 & 1 \\
\hline F43.2 & Adjustment disorder & 0 & 2 & 2 \\
\hline F44.3 & Trance and possession disorder & 0 & 1 & 1 \\
\hline F44.4 & Dissociative motor disorder & 1 & 24 & 25 \\
\hline $\mathrm{F} 45$ & Somatoform disorder & 0 & 1 & 1 \\
\hline G40 & Epilepsy & 2 & 0 & 2 \\
\hline X60-X84 & Intentional self harm; suicide & 2 & 1 & 3 \\
\hline G43 & Migrane & 0 & 1 & 1 \\
\hline \multirow[t]{2}{*}{ G44 } & Other headache syndromes & 0 & 1 & 1 \\
\hline & No psychiatric diagnosis & 0 & 2 & 2 \\
\hline
\end{tabular}

\section{DISCUSSION}

We found the psychiatric referral rate from the emergency to be $8.46 \%$. Study done in Guy's hospital, London from 1968 to 1969 showed the psychiatric referral rate from emergency department to be $2.2 \%$. Study done in Nehru hospital, Chandigarh in 1981 showed the referral rate to be $6.3 \%$. ${ }^{3}$ A study done in 1994 in Saudi Arab showed referral rate to be $6.3 \%$. This suggests that with time the psychiatric referral rate is also in the increasing trend.

In our study more referred patients were female with male to female ratio of $1: 1.78$. Other similar studies shows mixed result with some study showing male predominance ${ }^{3,4,6,7}$, while other showing equal ${ }^{8}$ or female predominance. ${ }^{2}$ More patients fell in the age group of 20- 24 years (19\%) and 25-29yrs (19\%). This is in accordance with other studies which show more patients falling in the age group 20-29years. ${ }^{1,3,6}$

Regarding marital status $74 \%$ of our patients were married. Study done in India also showed married participants. ${ }^{3}$ While some studies from western setting show single, separated or divorced $^{2,7}$ as most common participants, other shows married ${ }^{1}$ as common.

Family members were the source of referral for emergency visit in majority of the patients (74\%). Majority of other studies too shows family members ${ }^{3}$ or patient themelves as the source of referral. ${ }^{1,2,4}$

Regarding the presenting complaints irrelevant talks was the most common presenting complaint $(29 \%)$ in our study. In contrast to our study, somatic symptoms ${ }^{3}$ and disturbed behaviour $^{6}$ was the most common presenting complaint.

Dissociative Disorders (neurotic, stress related and somatoform) was most common diagnosis followed by substance (alcohol) use disorder. Many similar studies show depressive disorder as most common psychiatric diagnosis. ${ }^{2,4}$ Some shows substance (alcohol) use disorder ${ }^{6}$ and neurotic stress related and somatoform disorder ${ }^{7}$ as most common psychiatric diagnosis.

\section{CONCLUSION}

- Family members are able to identify mental or behavioural problems warranting visit to the emergency department.

- Awareness among the emergency doctors regarding psychiatric illness can increase the psychiatric referral rate so that more needy persons can get the services.

\section{ACKNOWLEDGEMENTS}

We are thankful to the Universal College of Medical Sciences and Teaching Hospital for providing us the opportunity to conduct this study.

\section{REFERENCES}

1. Knop J, Sogaard U, Sorensen AS, Schultz V et al. "Psychiatric emergency service in the city of Copenhagen". Nord J Psychiatry 1991; 45:119-127.

http://dx.doi.org/10.3109/08039489109103275

2. Lund $O$, Hoyersten JG, Lund A. Bergen psychiatric emergency room: The patients' sociomedical characteristics, patterns of use, and management. Nord J Psychiatry 1997; 51:423-429. http://dx.doi.org/10.3109/08039489709090739

3. Kelkar DK, Chaturvedi SK, Malhotra S. A study of emergency psychiatric referrals in a teaching general hospital.Indian $J$ Psychiatry. 1982; 24(4):366-69.

4. B.H.Anstee. Psychiatry in the casualty department.Brit. J. 
Psychiat (1972), 120, 625-9.

5. Alhamad A.M., Al-Sawaf M.H., Osman A.A., Ibraham I.S. "Differential aspects of consultation-liaison psychiatry in a Saudi hospital". Eastern Mediterranean Health J. Vol.12, Nos 3/4, 2006, P318-20.

6. Shakya DR, Shyangwa P M, Shakya R. Psychiatric Emergencies in a Tertiary Care Hospital. JNMA JNepal Med Assoc. 2008 JanMar;47(169):28-33.
7. Hatfield B, Spurrell M,Perry A. "Emergency referrals to an acute psychiatric service: demographic, social and clinical characteristics and comparision with those receiving continuing services". Journal of Mental Health (2000) 9,3,305-317.

8. Johansen I.H, LivMellesdal R.N., Jørgensen H.A , Hunskaar S. Nordic Journal of Psychiatry. "Admissions to a Norwegian emergency psychiatric ward: patient characteristics and referring agents. A prospective study". Feb 2012, Vol. 66 (1) , P 40-48. 